\title{
ANALISIS MAHASISWA PROGRAM STUDI PENDIDIKAN GEOGRAFI DALAM PERSPEKTIF SPASIAL SEBAGAI UPAYA PENJARINGAN MAHASISWA BARU
}

\author{
Ajun Purwanto', Paiman', Dony Andrasmoro ${ }^{3}$ \\ ${ }^{1,2,3}$ Pendidikan Geografi, IKIP PGRI Pontianak \\ Jalan Ampera Nomor 88, Pontianak, Kalimantan Barat \\ e-mail: ajunpurwanto@ikippgriptk.ac.id
}

\begin{tabular}{|c|c|c|c|c|c|}
\hline $\begin{array}{c}\text { Submitted } \\
2021-07-30\end{array}$ & $\begin{array}{c}\text { Accepted } \\
2021-11-22\end{array}$ & $\begin{array}{l}\text { Published } \\
2021-12-01\end{array}$ & open $\partial_{\text {Access }}$ & (c) (i) (8) & asinta 3 \\
\hline
\end{tabular}

\begin{abstract}
Abstrak
Penelitian bertujuan untuk mengetahui profil dan menganalisis persebaran spasial mahasiswa Program Studi Pendidikan Geografi angkatan 2016-2019. Metode penelitian yang digunakan adalah deskriptif. Bentuk penelitian survei dengan responden sebanyak 196. Teknik pengambilan data menggunakan komunikasi tidak langsung, alat yang digunakan adalah angket. Data yang digunakan yaitu nama, asal, agama, jenis kelamin, pendidikan terakhir, pekerjaan, dan pendapatan orang tua. Teknik pengambilan sampel dengan stratified sampling. Teknik analisis data menggunakan deskriptif kuantitatif dan persentase. Hasil penelitian menunjukkan mahasiswa Program Studi Pendidikan Geografi paling banyak beragama Islam 95 orang; berjenis kelamin wanita 144 orang; pendidikan dari SMA Jurusan IPS 166 orang; pekerjaan orang tua petani 96 orang; penghasilan rata-rata orang tua Rp760.000,00/bulan; informasi tentang Program Studi Pendidikan Geografi paling banyak didapatkan dari saudara sebanyak 74 orang; motivasi masuk karena berkeinginan untuk mengetahui seluk-beluk bumi sebanyak 64 orang. Persebaran mahasiswa Program Studi Pendidikan Geografi menunjukkan pola distribusi yang menyebar.
\end{abstract}

Kata Kunci: analisis mahasiswa program studi; penjaringan mahasiswa baru; perspektif spasial.

\begin{abstract}
The research aimed to determine the profile and analyze the spatial distribution of students from the 2016-2019 Geography Education Study Program. The research method used descriptive. The form of the survey with 196 respondents. The data collection technique used indirect communication, the tool used is a questionnaire. The data used name, origin, religion, gender, last education, occupation, and parents' income. The sampling technique used stratified sampling. The data analysis technique used descriptive quantitative and percentage. The results showed that the most students of the Geography Education Study Program were 95 Muslims; female sex 144 people; education from SMA majoring in Social Sciences 166 people; the occupation of the farmer's parents were 96 people; the average income of parents was Rp760,000.00/month; Information about the Geography Education Study Program was mostly obtained from relatives as many as 74 people; The motivation to enter was because they want to know the ins and outs of the earth 64 people. The distribution of students from the Geography Education Study Program showed a distributed distribution pattern.
\end{abstract}

Keywords: analysis of study program students; new student screening; spatial perspective. 
Edukasi: Jurnal Pendidikan, Volume 19 Nomor 2 Tahun 2021

Analisis Mahasiswa Program Studi Pendidikan Geografi.......

Ajun Purwanto, Paiman, Dony Andrasmoro

Halaman 174-186

\section{PENDAHULUAN}

Aspek pemerataan dan perluasan akses pendidikan adalah satu satu aspek titik berat pembangunan pendidikan nasional Indonesia (Bappenas, 2019a). Prioritas nasional pada satuan pendidikan adalah usaha memperluas daya tampung untuk siswa dan merupakan arah dari kebijakan pemerintah yang memberikan kesempatan yang sama kepada masyarakat khususnya siswa yang berbeda-beda secara gender, tempat tinggal, ekonomi maupun sosial, kemampuan intelektual, dan kondisi fisik (Bappenas, 2019b). Tujuan dari kebijakan tersebut untuk meningkatkan jumlah penduduk Indonesia dapat belajar sepanjang hayat (Hasami \& Buang, 2018), serta peningkatan daya saing bangsa untuk meningkatkan indeks pembangunan manusia (IPM) di era global (Susila \& Lestari, 2016).

IPM dapat ditingkatkan jika kesempatan untuk memperoleh pendidikan dapat dirasakan masyarakat di berbagai wilayah (Siswati \& Hermawati, 2018). Upaya memberikan kesempatan pendidikan dilakukan oleh berbagai isntitusi pendidikan lewat strategi masing-masing (Suriansyah, 2015). Strategi-strategi tersebut esensinya adalah untuk mendapatkan dan meningkatkan jumlah mahasiswa yang tersebar di berbagai wilayah. Persebaran mahasiswa dapat dijadikan sebagai dasar evaluasi sistem promosi dan perekrutan dalam mekanisme penjaringan mahasiswa (Wijaya, 2018). Distribusi mahasiswa yang berasal dari berbagai kabupaten dapat menjadi basis sekaligus strategi untuk meningkatkan kuantitas mahasiswa. Pendataan distribusi spasial mahasiswa sangat penting karena dapat diketahui komposisi dan karakteristik setiap calon maupun yang sudah berstatus mahasiswa.

Calon mahasiswa sebagai konsumen atau penikmat fasilitas pendidikan dalam menentukan pilihan perguruan tinggi ternyata banyak pertimbangan sesuai dengan keinginan dan motivasinya. Penentuan atau pengambilan keputusan dari masing-masing individu antara lain besarnya harga/biaya selama kuliah, strata sosial, rangking perguruan tingi, jarak/lokasi, kebudayaan, saran atau referensi, dukungan keluarga, sifat-sifat pribadi (personal traits), kondisi fisik, motivasi, sikap, dan persepsi (Amirsyah \& Cholila, 2017; Susila \& Lestari, 2016; Suryani, 2013). Faktor lain yang menjadi dasar pertimbangan calon mahasiswa dalam 
memutuskan masuk perguruan tinggi yaitu kinerja lembaga, program studi yang diselenggarakan, keadaan fisik kampus, tata kelola, serta faktor-faktor lain yang ada pada diri calon mahasiswa seperti faktor psikologi, sosial maupun budaya (Kusuma \& Winarno, 2018; Susila \& Lestari, 2016), latar belakang sosial ekonomi, motivasi, acuan, kualitas, dan lulusan yang dihasilkan (Akhiri, 2021; Susila \& Lestari, 2016).

Perlu adanya sebuah analisis dalam menjawab pertimbangan-pertimbangan yang akan menjadi dasar keputusan calon mahasiswa untuk masuk perguruan tinggi. Analisis dapat diaplikasikan dalam berbagai kondisi yang menuntut adanya sebuah informasi yang jelas untuk mendapatkan gambaran yang lebih jelas dalam memecahkan sebuah persoalan. Analisis dapat dilakukan terhadap beberapa aspek yang ada di sekitar atau lingkungan, yang salah satunya adalah dapat diterapkan pada aspek ruang (spasial). Analisis spasial atau ruang dapat dikaitkan dengan fenomena geografi, sosial, ekonomi maupun fenomena yang lain (Igarta \& Handayani, 2020).

Analisis keruangan (analisis spasial) adalah suatu analisis yang berorientasi pada suatu tempat atau lokasi (Susandi, 2020). Analisis spasial menitikberatkan pada tiga unsur geografi, yaitu gerakan (movement), kaitan (interaction), dan jarak (distance) (Ronggowulan, 2013). Aplikasi analisis spasial dapat diterapkan di berbagai disiplin ilmu dan kajian. Fenomena ataupun objek yang ada di permukaan bumi dapat diterapkan analisis keruangan (spatial analysis) (Rohsulina \& Rahman, 2015). Penerapan analisis spasial dalam sektor pendidikan salah satunya adalah analisis persebaran asal mahasiswa. Analisis persebaran asal mahasiswa sangat penting karena semakin bervariasinya persebaran asal mahasiswa, maka akan semakin beragam pula karakteristik mahasiswa yang berada di sebuah kampus, khususnya di IKIP PGRI Pontianak.

Sudut pandang atau kerangka analisis suatu pendekatan keruangan merupakan cara memandang atau menganalisis suatu persoalan yang menekankan pada keberadaan ruang (spatial) sebagai penekananya (Fadilah et al., 2018; Christiawan, 2017). Keberadaan ruang dalam disiplin ilmu geografi dapat dilihat dari struktur (spatial structure), pola (spatial pattern), dan proses (spatial 
Edukasi: Jurnal Pendidikan, Volume 19 Nomor 2 Tahun 2021

Analisis Mahasiswa Program Studi Pendidikan Geografi.......

Ajun Purwanto, Paiman, Dony Andrasmoro

Halaman 174-186

processes) (Rahman \& Partono, 2018; Suasti \& Ahyuni, 2016). Pola (pattern) adalah ciri khas penyebaran gejala tertentu di dalam suatu wilayah (Rohsulina \& Rahman, 2015; Ronggowulan, 2013). Pola keruangan salah satunya dilakukan melalui pengamatan gejala atau fenomena yang didasarkan pada kenampakan titik, kenampakan garis, dan kenampakan area atau wilayah (Putra, 2019).

Analisis spasial merupakan langkah yang perlu dilakukan dalam pengambilan keputusan (Suhendar, 2015) sekaligus sebagai evaluasi pengambilam keputusan agar menjadi lebih baik lagi. Melalui analisis spasial terhadap mahasiswa dapat dikumpulkan data dan fakta bagaimana kondisi bahkan profil mahasiswa yang ada. Alasan dilakukannya penelitian adalah masih sedikitnya peminat anak-anak lulusan SMA ataupun SMK untuk kuliah di IKIP PGRI Pontianak, terutama Program Studi Pendidikan Geografi. Analisis spasial dapat memperlihatkan gambaran keterkaitan antarwilayah (Adil, 2015) dan karakteristiknya, sehingga dijadikan sebagai dasar dalam evaluasi perekrutan mahasiswa baru untuk meningkatkan kuantitas mahasiswa Program Studi Pendidikan Geografi yang jumlah mahasiswanya sedikit.

Berdasarkan kondisi yang telah diuraikan, maka Program Studi Pendidikan Geografi dapat memaksimalkan langkah-langkah promosi di wilayah-wilayah yang masih sedikit peminatnya untuk kuliah di IKIP PGRI Pontianak, terutama Program Studi Pendidikan Geografi. Tujuan dari penelitian untuk mengetahui profil mahasiswa dan menganalisis persebaran spasial mahasiswa Program Studi Pendidikan Geografi IKIP PGRI Pontianak angkatan 2016-2019.

\section{METODE}

Metode yang digunakan dalam penelitian adalah deskriptif, pendekatan yang digunakan adalah kuantitatif dengan bentuk survei. Subjek penelitian adalah mahasiswa Program Studi Pendidikan Geografi angkatan 2016-2019 IKIP PGRI Pontianak. Jumlah responden sebanyak 196 mahasiswa angkatan 2016-2019 yang sampel diambil menggunakan teknik stratified sampling. Teknik pengumpulan data menggunakan komunikasi tidak langsung dan alat pengambilan data menggunakan angket. Isi dari angket adalah tentang karakteristik mahasiswa, 
meliputi: nama, asal, umur, agama, jenis kelamin, pendidikan terakhir, pekerjaan orang tua, dan pendapatan orang tua. Rata-rata umur mahasiswa dicari dengan cara menjumlahkan secara total semua umur mahasiswa dibagi dengan jumlah mahasiswa. Pemetaan penyebaran karakteristik profil mahasiswa dalam penelitian menggunakan Sistem Informasi Geografi (SIG) dengan ArcVeiw 10.8. Teknik analisis data menggunakan analisis deskriptif kuantitatif dan persentase dengan rumus (1).

Persentase $(\%)=($ jumlah bagian $) /($ jumlah total $) \times 100 \%$

\section{HASIL DAN PEMBAHASAN}

Berdasarkan hasil penelitian, rata-rata umur mahasiswa angkatan 2016 adalah 20 tahun, angkatan 2017 adalah 19 tahun, angkatan 2018 adalah 18 tahun, dan angkatan 2017 adalah 17 tahun. Berdasarkan data tersebut, diketahui rata-rata usia mahasiswa Program Studi Pendidikan Geografi angkatan 2016-2019 adalah 19 tahun. Agama yang dianut mahasiswa paling banyak adalah Islam. Mahasiswa yang beragama Islam sebanyak 95 orang (48,7\%), Katolik sebanyak 79 orang (40,6\%), dan Kristen Protestan sebanyak 22 orang (10,7\%). Persebaran keyakinan yang dipeluk oleh mahasiswa Program Studi Pendidikan Geografi angkatan 20162019 dapat dilihat di Gambar 1.

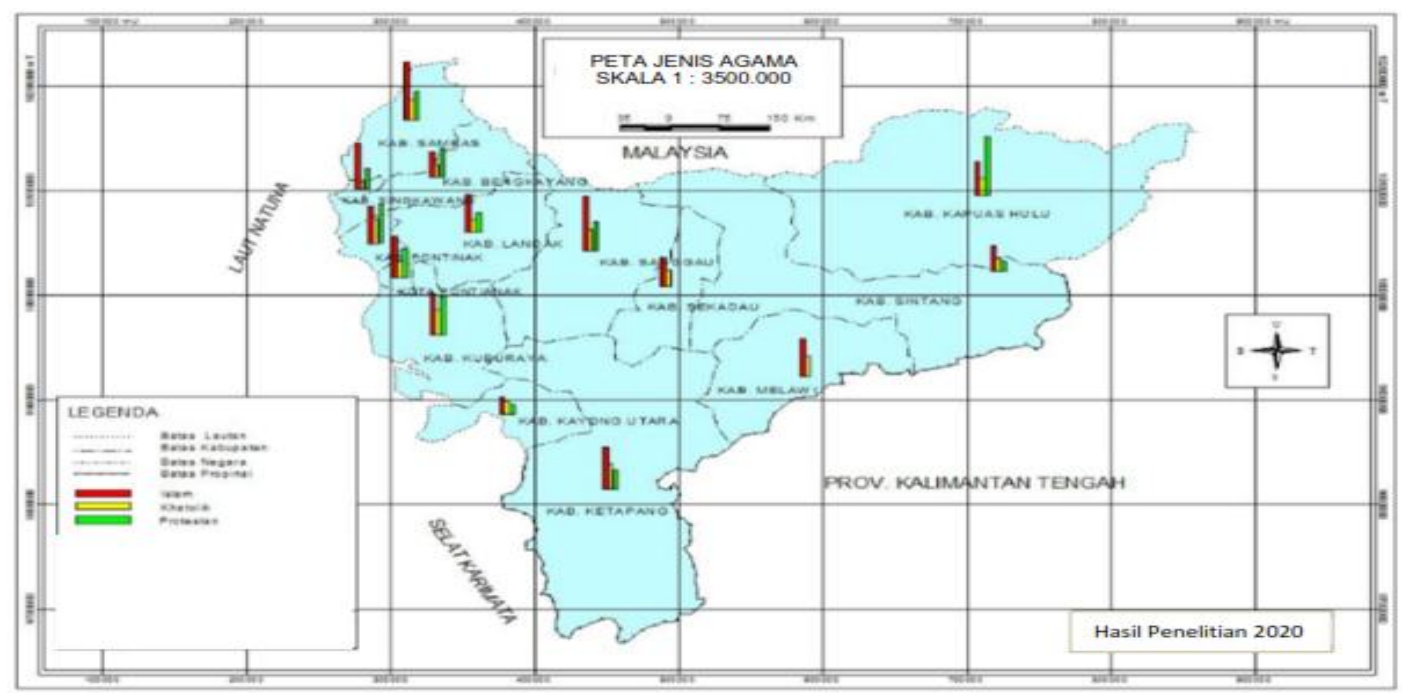

Gambar 1 Persebaran Agama Mahasiswa 
Edukasi: Jurnal Pendidikan, Volume 19 Nomor 2 Tahun 2021

Analisis Mahasiswa Program Studi Pendidikan Geografi.......

Ajun Purwanto, Paiman, Dony Andrasmoro

Halaman 174-186

Mahasiswa asal Sambas paling banyak yang beragama Islam, sedangkan mahasiswa dari Kayong Utara yang sedikit. Mahasiswa yang beragama Kristen Protestan paling banyak dari Kabupaten Kapuas Hulu, sedangkan Sanggau dan Melawi tidak ada. Makna yang tersirat berdasarkan karakteristik agama adalah bahwa mahasiswa Program Studi Pendidikan Geografi masing-masing sudah mempunyai dasar kekuatan spiritual yang melandasi dalam setiap aktivitasnya selama belajar di kampus. Berdasarkan jenis kelamin mahasiswa, paling banyak adalah wanita. Mahasiswa wanita sebanyak 196 orang 144 (73,6\%) dan laki-laki sebanyak 52 orang (26,4\%). Lebih jelasnya berdasarkan jenis kelamin, persebaran mahasiswa dapat dilihat di Gambar 2.

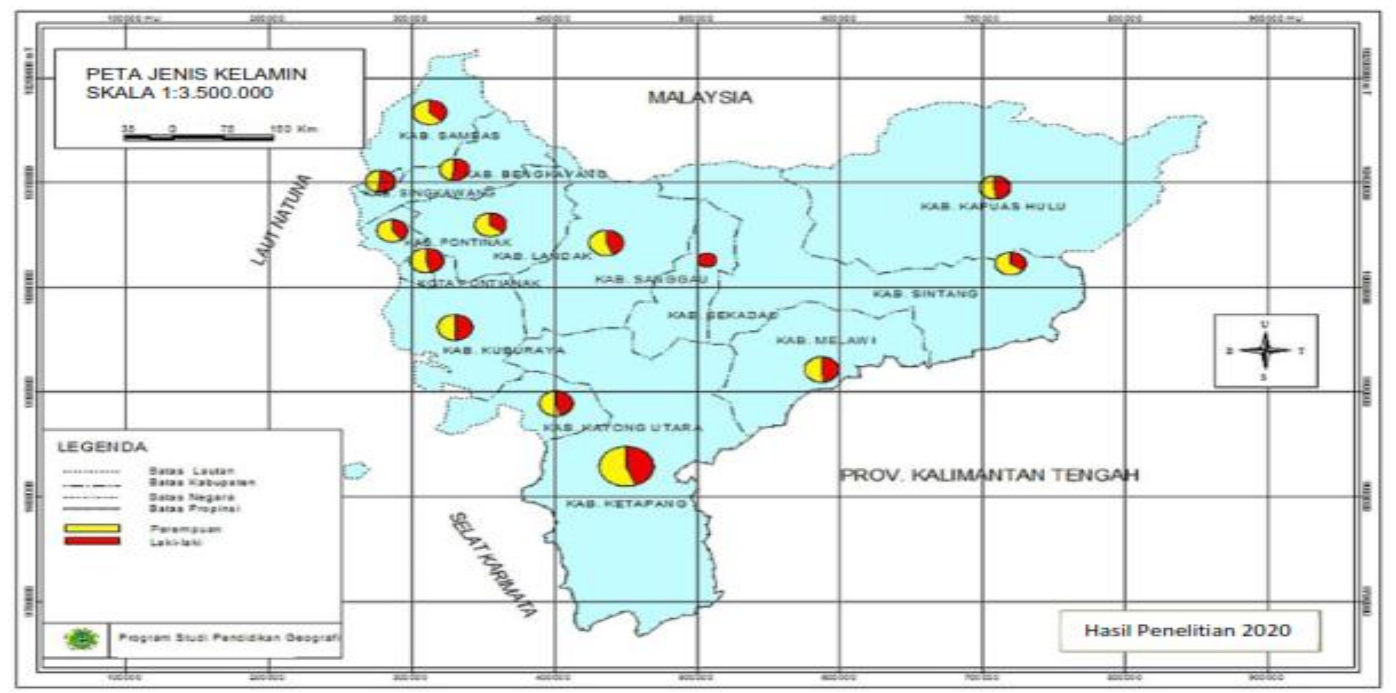

Gambar 2 Mahasiswa Berdasarkan Jenis Kelamin

Mahasiswa dengan jenis kelamin wanita paling banyak berasal dari Landak, Ketapang, Pontianak, Sanggau, dan Sintang, sedangkan mahasiswa laki-laki yang paling banyak dari Singkawang dan Bengkayang. Berdasarkan hal tersebut, maka dapat disimpulkan bahwa banyaknya jenis kelamin wanita di Program Studi Pendidikan Geografi karena untuk menjadi guru, khususnya guru Geografi, perlu kesabaran dan sifat keibuan yang dimiliki oleh wanita. Tingkat pendidikan responden yang dimaksud dalam penelitian yaitu tahun sukses atau pendidikan terakhir yang ditamatkan oleh mahasiswa. Pendidikan terakhir mahasiswa paling banyak berasal dari SMA Jurusan IPS dengan jumlah 166 responden (84,6\%), 20 orang $(10,2 \%)$ dari SMA Jurusan IPA, sedangkan SMK menempati urutan yang 
paling sedikit, yaitu 10 orang $(5,1 \%)$. Pendidikan terakhir mahasiswa dapat dilihat di Gambar 3.

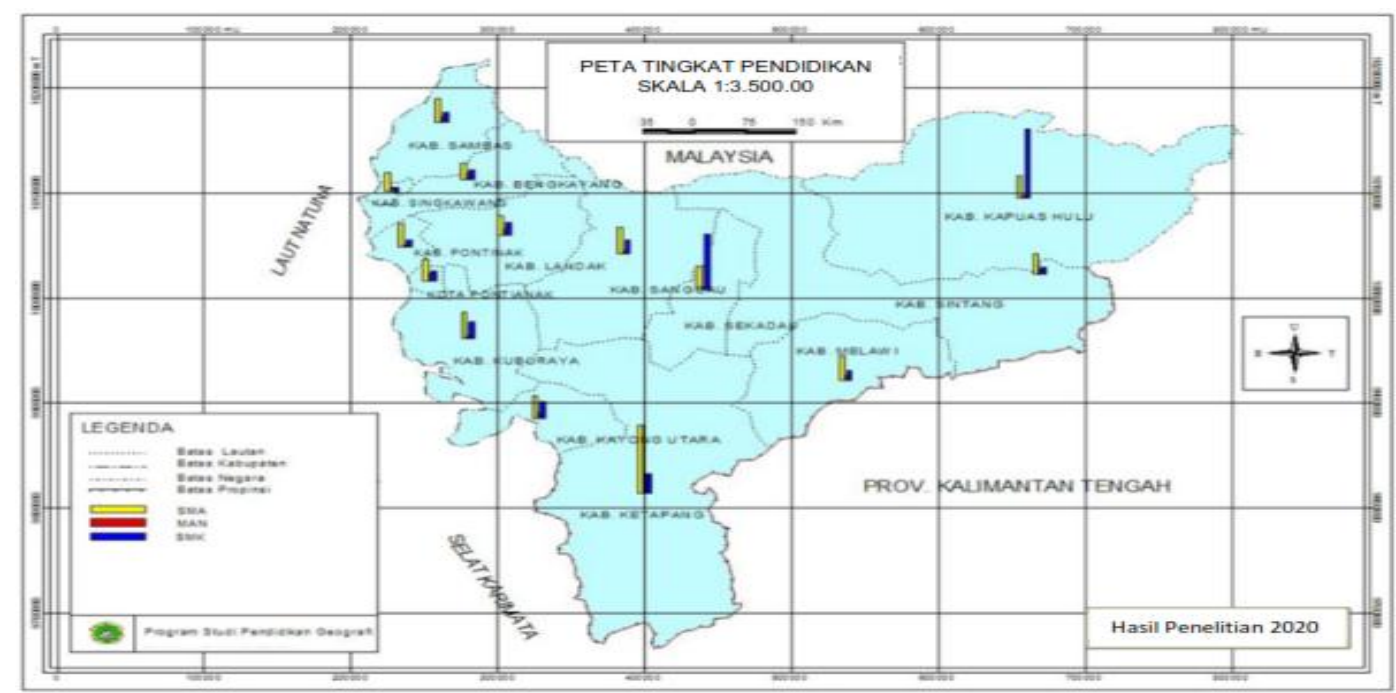

Gambar 3 Mahasiswa Berdasarkan Tingkat Pendidikan

Berdasarkan banyaknya jumlah masiswa dengan latar belakang pendidikan SMA Jurusan IPS, maka sebenarnya terdapat relevansi antara pendididikan yang ditamatkan di tingkat pendidikan atas dan program studi yang diambil karena sama-sama dalam konsursium ilmu pengetahuan sosial. Mahasiswa yang berlatar belakang SMA Jurusan IPA tidak kesulitan dalam menyesuaiakan dengan mata kuliah yang ada karena untuk kompetensi-kompetensi di Program Studi Pendidikan Geografi juga banyak yang dasarnya adalah mata kuliah yang sifatnya science dan alam. Namun, untuk yang berpendidikan SMK akan lebih sulit dalam menyesuaiakan diri dengan mata kuliah yang ada, sehingga akan lebih baik diberikan matrikulasi agar menyesuaikan pembelajaran Pendidikan Geografi.

Pekerjaan pokok orang tua mahasiswa bervariasi, terdiri dari petani, guru, pedagang, swasta, TNI/POLRI, dan lain-lain. Pekerjaan orang tua mahasiswa sebagai petani sebanyak 96 orang $(49,2 \%)$, swasta sebanyak 41 orang $(20,8 \%)$, lain-lain sebanyak 30 orang $(15,2 \%)$, guru sebanyak 20 orang $(10,2 \%)$, pedagang sebanyak 7 orang $(3,6 \%)$, dan paling sedikit adalah TNI/Polri sebanyak 2 orang (1\%). Sebaran pekerjaan pokok orang tua mahasiswa dapat dilihat di Gambar 4. Pekerjaan orang tua mahasiswa yang paling banyak berasal dari petani karet, sawit, dan tani ladang berpindah. Kondisi tersebut wajar karena banyak 
Edukasi: Jurnal Pendidikan, Volume 19 Nomor 2 Tahun 2021

Analisis Mahasiswa Program Studi Pendidikan Geografi.......

Ajun Purwanto, Paiman, Dony Andrasmoro

Halaman 174-186

mahasiswa yang memang berasal dari daerah atau desa yang mayoritas penduduknya bekerja sebagai petani. Dikaitkan dengan keberlangsungan studi mahasiswa, secara umum memang akan sangat berpengaruh. Penghasilan dari pekerjaan sebagai petani yang tidak tetap akan dapat menghambat keberlangsungan studi terkait dengan keuangan kuliah. Sebagai petani akan sangat bergantung pada hasil bumi, dimana panen, harga, dan produktivitasnya selalu mengalami pasang-surut, bergantung pada musim, harga pasar, dan mahalnya obat-obatan pertanian. Kondisi tersebut sangat berpengaruh terhadap kelancaran pembayaran keuangan mahasiswa.

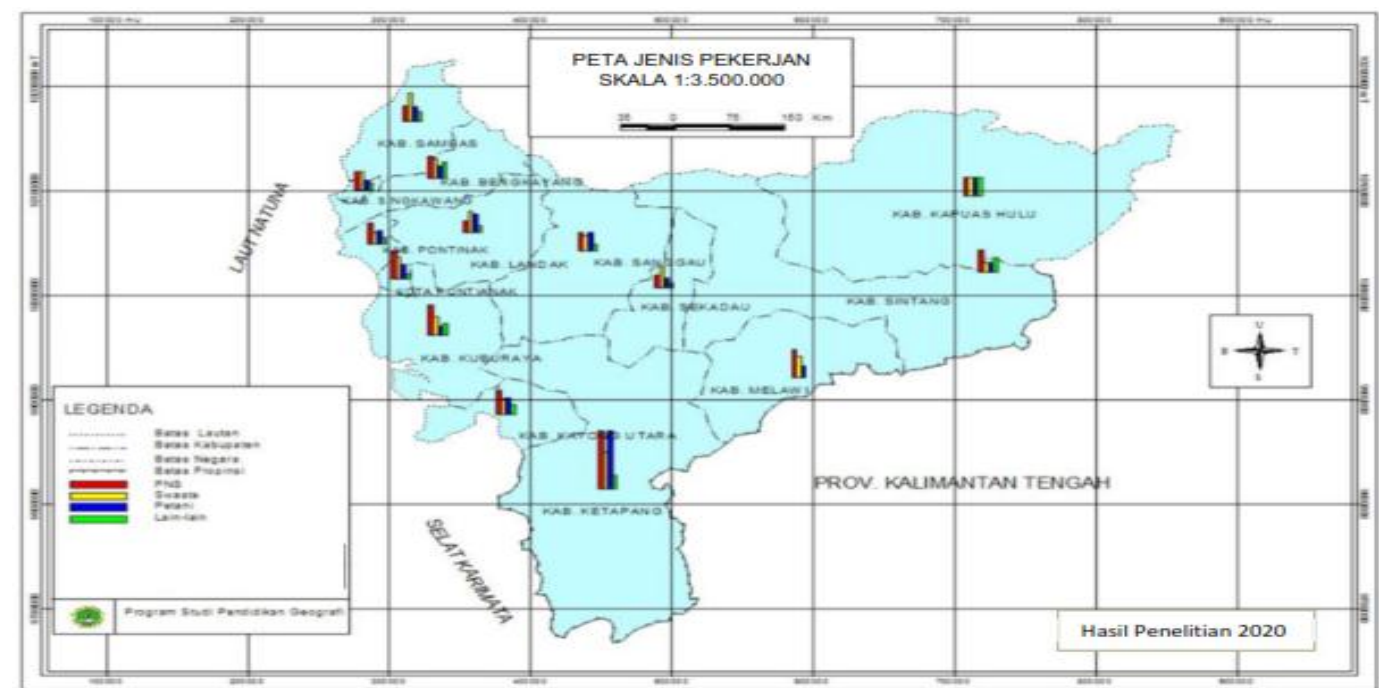

Gambar 4 Jenis Pekerjaan Orang Tua Mahasiswa

Penghasilan orang tua mahasiswa yang paling besar berkisar antara Rp500.000,00 sampai Rp1.000.000,00/bulan sebanyak 99 orang (50,3\%). Penghasilan orang tua mahasiswa yang lebih dari atau sama dengan Rp4.000.000,00/bulan sebanyak 7 orang $(3,6 \%)$. Apabila dirata-rata penghasilan dari orang tua mahasiswa adalah Rp760.000,00. Angka tersebut diperoleh dari total penghasilan orang tua dibagi dengan 196 mahasiswa. Penghasilan banyak juga digunakan untuk keperluan rumah tangga, sosial kemasyarakatan, apalagi sekarang harga-harga barang kebutuhan rumah tangga semua meningkat, sehingga untuk bisa membayar keuangan kuliah perlu rezeki yang lebih. Hal tersebut tentu saja akan berpengaruh terhadap kelancaran pembayaran keuangan mahasiswa dalam proses studinya. 
Informasi tentang Program Studi Pendidikan Geografi banyak didapatkan dari saudara. Banyaknya responden yang mendapatkan informasi saudara sebanyak 74 orang $(37,6 \%)$. Paling sedikit informasi didapatkan dari website dan lain-lain, yaitu sebanyak 9 orang (4,6\%). Informasi dari sumber lain-lain antara lain dari teman yang masih kuliah di IKIP PGRI Pontianak, dosen pembimbing pengenalan lapangan, dan guru praktik pengenalan lapangan. Berdasarkan data yang diperoleh, terlihat bahwa dalam memperoleh informasi lewat website sangat minim, maka perlu adanya sosialisasi yang lebih intensif melalui media sosial yang ada, seperti Facebook, WhatsApp, dan Instgram. Persentase informasi mahasiswa Program Studi Pendidikan Geografi dapat dilihat di Gambar 5.
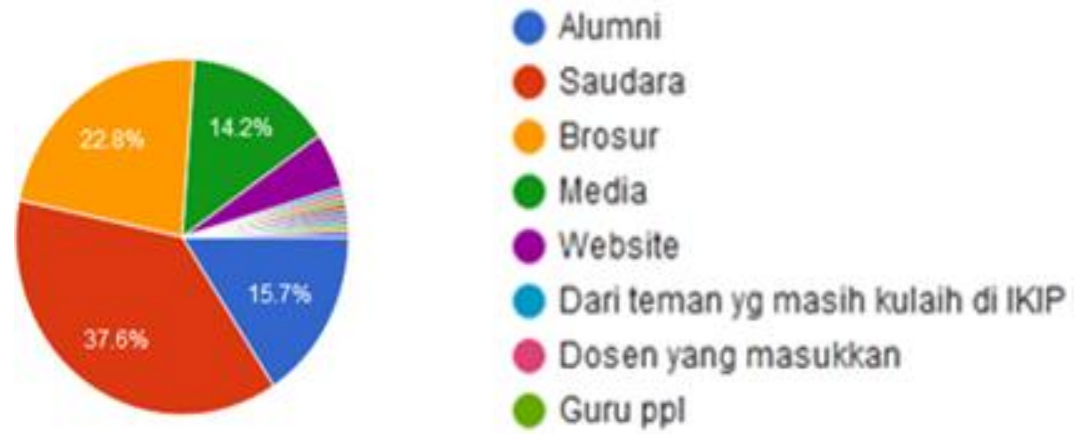

\section{Gambar 5 Persentase Perolehan Informasi}

Motivasi atau keinginan, arah, dan alasan yang mendasari mahasiswa tertarik masuk Program Studi Pendidikan Geografi juga bervariasi. Beberapa motivasi tersebut yaitu lebih mudah mencari pekerjaan, berkesempatan menjadi guru favorit, dapat dengan mudah mengetahui seluk-beluk bumi, dapat mengetahui iklim global, dapat mengetahui kondisi dunia, serta mendapatkan wawasan yang lebih luas. Motivasi yang paling banyak adalah karena keinginan untuk mengetahui seluk-beluk bumi yaitu sebanyak 64 orang (22,8\%). Paling sedikit motivasi atau keinginan arah dan alasannya adalah untuk mengetahui iklim global yaitu sebanyak 6 orang $(3,1 \%)$. 


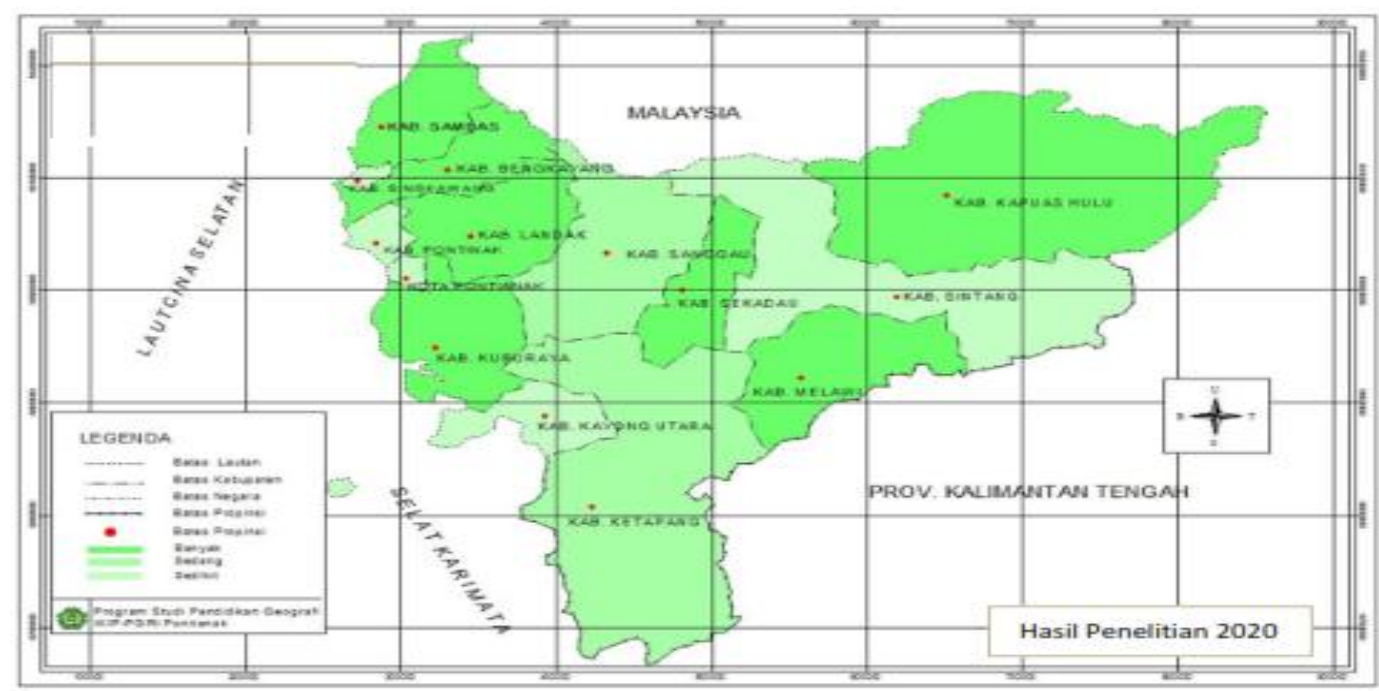

\section{Gambar 6 Persebaran Mahasiswa}

Pola distribusi mahasiswa Program Studi Pendidikan Geografi adalah menyebar dengan frekuensi yang berbeda-beda satu kabupaten dengan kabupaten yang lain. Namun, frekuensi jumlah penyebarannya relatif sama. Mahasiswa yang berasal Kabupaten Sambas paling banyak dan dari Kabupaten Mempawah jumlahnya paling sedikit. Pola distribusi menyebar memberikan peluang untuk pengenalan Program Studi Pendidikan Geografi banyak dikenal di berbagai daerah asal mahasiswa. Masih perlu adanya sosialisasi pengenalan program studi yang lebih intensif agar Program Studi Pendidikan Geografi lebih dikenal secara luas dan lebih merata.

\section{SIMPULAN}

Karakteristik mahasiswa Program Studi Pendidikan Geografi angkatan 2016-2019, yaitu: usia rata-rata 19 tahun; paling banyak beragama Islam; paling banyak berjenis kelamin wanita; pendidikan terakhir paling banyak berasal dari SMA Jurusan IPS; pekerjaan orang tua mahasiswa paling banyak adalah petani; dan penghasilan rata-rata orang tua adalah Rp760.000,00/bulan. Informasi tentang Program Studi Pendidikan Geografi paling banyak didapatkan dari saudara dan motivasi masuk program studi paling banyak karena berkeinginan untuk mengetahui seluk-beluk bumi. Mahasiswa paling banyak bersal dari Kabupaten Sambas sedangkan yang paling sedikit berasal dari Kabupaten Mempawah. 
Persebaran mahasiswa Program Studi Pendidikan Geografi menunjukkan pola distribusi yang menyebar.

\section{UCAPAN TERIMA KASIH}

Terima kasih peneliti ucapkan kepada Lembaga Penelitian dan Pengabdian Kepada Masyarakat IKIP PGRI Pontianak yang telah mendukung pendanaan dalam penelitian dasar dengan nomor kontrak 007/L.202/PNK/III/2020.

\section{DAFTAR PUSTAKA}

Adil, A. (2015). Analysis Proximity Menentukan Lokasi Perkebunan di Lombok Barat. MATRIK: Jurnal Manajemen, Teknik Informatika dan Rekayasa Komputer, 15(1), 7-12. https://doi.org/10.30812/matrik.v15i1.27.

Akhiri, S. (2021). Faktor-Faktor yang Mempengaruhi Keputusan Mahasiswa Kuliah di STIE Prabumulih. Management Studies and Entrepreneurship Journal (MSEJ), 2(2), 123-132. https://doi.org/10.37385/msej.v2i2.202.

Amirsyah, S., \& Cholila, N. (2017). Analisis Faktor-Faktor yang Mempengaruhi Keputusan Mahasiswa dalam Memilih Universitas Islam Riau sebagai Tempat Belajar. Jurnal Ekonomi KIAT, 28(2), 111-130. https://doi.org/10.25299/kiat.2017.vol28(2).2899.

Bappenas. (2019a). Rencana Pembangunan Jangka Menengah Nasional 20202024. Jakarta: Bappenas.

Bappenas. (2019b). Visi dan Arah Pembangunan Jangka Panjang. Jakarta: Bappenas.

Christiawan, P. I. (2017). Inovasi Pendidikan Bencana Berbasis Pendekatan Spasial di Indonesia. Jurnal Media Komunikasi Geografi, 15(1), 1-18. http://dx.doi.org/10.23887/mkg.v15i1.11419.

Fadilah, N., Zulkarnain, Z., \& Suwarni, N. (2018). Profil Anak di Bawah Usia Kerja yang Bekerja sebagai Penjual Koran di Simpang Pramuka. Jurnal Lampung University, 1(1),1-13.

Hasami, H., \& Buang, N. A. (2018). Keberkesanan Program Pembelajaran Sepanjang Hayat (PSH) terhadap Pengetahuan dan Tahap Kemahiran 
Edukasi: Jurnal Pendidikan, Volume 19 Nomor 2 Tahun 2021

Analisis Mahasiswa Program Studi Pendidikan Geografi.......

Ajun Purwanto, Paiman, Dony Andrasmoro

Halaman 174-186

Pelajar Kolej Komuniti (The Effectiveness of the Lifelong Learning Programme (PSH) Towards Knowledge and Skill Levels of Students Community College). Jurnal Pendidikan Malaysia (Malaysian Journal of Education), 43(1SI), 89-106. http://dx.doi.org/10.17576/JPEN-2018-43.0310.

Igarta, K. R. R., \& Handayani, F. (2020). Analisis Spasial Sektor Pariwisata di Provinsi Kalimantan Selatan. Jurnal Borneo Administrator, 16(1), 81-100. https://doi.org/10.24258/jba.v16i1.628.

Kusuma, R. A., \& Winarno, M. E. (2018). Efektivitas Waktu Pembelajaran Pendidikan Jasmani Olahraga dan Kesehatan di SMPN 11 Malang. Gelanggang Pendidikan Jasmani Indonesia, 2(2), 135-141. http://dx.doi.org/10.17977/um040v2i2p135-141.

Putra, I. K. A. (2019). Analisis Tingkat Kepercayaan Publik terhadap STIKI Ditinjau Asal Mahasiswa Berbasis SIG. Media Komunikasi Geografi, 20(1), 1-10. http://dx.doi.org/10.23887/mkg.v20i1.16747.

Rahman, M. S. K., \& Partono, B. (2018). Analisis Spasial Perbandingan Jumlah Anak Usia SD dan Ruang Kelas Kecamatan Bulu Kabupaten Sukoharjo. Jurnal Komunikasi Pendidikan, $\quad 1(1), \quad 1-9$. https://doi.org/10.32585/jkp.v1i1.11.

Rohsulina, P., \& Rahman, M. S. K. (2015). Analisis Persebaran Daerah Asal Mahasiswa Universitas Veteran Bangun Nusantara dengan Menggunakan Sistem Informasi Geografis (Sig). Geo Edukasi, 4(2), 10-18.

Ronggowulan, L. (2013). Persebaran Pelayanan Kesehatan Tingkat Pertama di Kabupaten Sukoharjo Tahun 2011. Skripsi: Surakarta: Universitas Negeri Sebelas Maret. Tidak dipublikasikan.

Siswati, E., \& Hermawati, D. T. (2018). Analisis Indeks Pembangunan Manusia (IPM) Kabupaten Bojonegoro. Jurnal Ilmiah Sosio Agribis, 18(2), 93-114. http://dx.doi.org/10.30742/jisa.v18i2.531.

Suasti, Y., \& Ahyuni, A. (2016). Kecerdasan Spasial dalam Pembelajaran dan Perencanaan Pembangunan. Proseding Seminar nasional Geografi.

Suhendar, S. (2015). Penyajian Informasi Temporal Menggunakan Metode Fuzzy 
System pada Mesin Database Spasial. Seminar Nasional Informatika (SEMNASIF).

Suriansyah, A. (2015). Strategi Kepemimpinan Kepala Sekolah, Guru, Orang Tua, dan Masyarakat dalam Membentuk Karakter Siswa. Jurnal Cakrawala Pendidikan, 34 (2), 234-247. https://doi.org/10.21831/cp.v2i2.4828.

Suryani, W. (2013). Faktor-Faktor yang Mempengaruhi Keputusan Mahasiswa Memilih Fakultas Ekonomi Universitas Islam Sumatera Utara Al Munawaroh Medan. Jurnal Ekonomi Modernisasi, 9(1), 33-48. https://doi.org/10.21067/jem.v9i1.196.

Susandi, D. (2020). Sistem Informasi Geografis untuk Analisa Spasial Potensi Lembaga Pendidikan Keterampilan. JSiI (Jurnal Sistem Informasi), 7(2), 123-131. https://doi.org/10.30656/jsii.v7i2.2380.

Susila, A. R., \& Lestari, E. P. (2016). Strategi Peningkatan Jumlah Mahasiswa Fakultas Ekonomi Universitas Terbuka dengan Pendekatan Geographic Information System. Jurnal UTFEKON, 5(1), 81-106.

Wijaya, E. (2018). Strategi Perekrutan Calon Mahasiswa Baru dengan Metode Roadshow pada Lembaga Pendidikan dan Pelatihan Kerja Smart Fast Education Pekanbaru. Jurnal Ilmiah Skylandsea, 2(2), 2012-2018. 